\section{Velocity Ratio}

\section{Aleksandr Zhigalin}

The Schmidt Institute of Physics of the Earth of the Russian Academy of Sciences (IPE RAS), Moscow, Russia

\section{Definition}

The relationship of elastic longitudinal wave (Vp-waves) velocity to shear wave (Vs-waves) velocity or the relationship of elastic shear wave (Vs-waves) velocity to longitudinal wave (Vp-waves) velocity.

\section{Characteristics}

In engineering seismology, the velocity ratio $\mathrm{Vp} / \mathrm{Vs}$ (TAU parameter) is considered as an indicator of the changes in stress state of rocks in the process of development of strong tectonic and volcanic earthquakes. It is established that deep fault zones, named gradiental zones, display rapid changes in the ratio $\mathrm{Vp} / \mathrm{Vs}$ with a change of the anomalies' sign (positive or negative). These can be considered as seismogenic zones. Relatively low values of $\mathrm{Vp} / \mathrm{Vs}$ ratio indicate increases in activity in the magmatic chambers of volcanos during their activization. The ratio of $\mathrm{Vp}$-waves velocity to Vs-waves velocity $(\mathrm{Vp} / \mathrm{Vs})$ is used in engineering seismology and engineering geology (Slavina et al. 2015).

The ratio of $\mathrm{Vp}$-waves velocity to Vs-waves velocity $(\mathrm{Vp} / \mathrm{Vs})$ is used in engineering seismology and engineering geology. In engineering geology, the velocity ratios $\mathrm{Vs} / \mathrm{Vp}$ and $\mathrm{Vp} / \mathrm{Vs}$ are used for definition of physic-technical characteristics of rocks. If the values of both ratios are known, it is possible to define dynamic modules of elasticity - Poisson's ratio $\mu$, the Young's modulus $\mathrm{E}$, and the shift modulus G. These characteristics are of interest at carrying out engineering surveys for construction. To define the Poisson's ratio $\mu$, it is necessary to know $\mathrm{Vs} / \mathrm{Vp}$ or $\mathrm{Vp} / \mathrm{Vs}$ ratios only; for definition of the Young's modulus $E$ and the shift modulus, $G$ it is necessary to know also the density of rocks. For definition of static modulus necessary for engineering calculations, empirical ratios or special diagrams are used (Nikitin 1981; Bondarev 1997).

\section{Cross-References}

- Earthquakes

$\checkmark$ Poisson's Ratio

$\checkmark$ Young's Modulus

\section{References}

Bondarev VI (1997) Seismic method of definition of physic-mechanical properties not rocky soils. USMGA, Ekaterinburg

Nikitin VN (1981) Bases of engineering seismicity. MSU, Moscow

Slavina LB, Kuchay MS, Lichodeev DV (2015) Assessment of kinematic parameter TAU behavior as indicator of the pressure variation on the example of the results of observations on Kamchatka and Caucasus. "Problems of complex geophysical monitoring of the Far East of Russia". On 27th Sept - 3rd Oct 2015, PetropavlovskKamchatsky 